\title{
Cholesterol Oxidation Products (COPs) in Ruminant Meat: A Biological and Pathological Approach: A Review
}

Hafid Nadia

10.18805/ajdfr.DR-134

\begin{abstract}
After slaughter, meat tissues lose their antioxidant defenses, and more complex oxidative processes are initiated to form COPs- oxygenated derivatives of cholesterol. The oxysterol content in meat and meat products depends on factors such as temperature, heating time, storage time, packing conditions, and illumination. The composition and content of polyunsaturated fatty acids (PUFAs) and the age and the sex of the animal also influence the COP rate. The most common oxysterols present in meat and its products are 7-ketocholesterol, 20a-hydroxycholesterol, 25-hydroxycholesterol and a, $\beta$-epoxycholesterol. Oxysterols participate in a number of biological activities, such as cholesterol metabolism, the regulation of membrane fluidity and intracellular signaling pathways, by the activation of specific mediators, such as LXR, SREBPs and OSBP/ORP. However, their role in inflammatory, apoptotic, mutagenic, carcinogenic, and toxic mechanisms can elucidate their effect on human health.
\end{abstract}

Keywords: Biological activities, Cholesterol, Human diseases, Oxysterols, Ruminant meat.

Asian Journal Of Dairy and Food Research (2019)

\section{INTRODUCTION}

M eat lipids are composed primarily of triglycerides (85\% of total lipids). They are also composed of phospholipids (12\% of total lipids) and cholesterol (Ch; $3 \%$ of total lipids) (Bonnet et al., 2010). The cholesterol level varies very little in muscles (Evrat-Goergel, 2005), which contains $40-80 \mathrm{mg}$ of cholesterol per $100 \mathrm{~g}$ of fresh weight (Gandemer, 1992).

Cholesterol is the most important sterol in animal fats. It is not only a precursor of bile acids, steroid hormones (progesterone, oestradiol and testosterone), adrenal hormones (cortisol and aldosterone) and vitamin D, but also a major component of cell membranes, in which it is intercalated between phospholipids and decreases membrane permeability to water-soluble molecules (Pommier, 2010). The distribution of cholesterol in the membranes is variable. For example, erythrocyte and myelin membranes contain similar molar concentrations of cholesterol and phospholipids, whereas membranes of high metabolic organelles, such as the sarcoplasmic reticulum and the inner mitochondrial membrane contain less cholesterol (Cullis and Hope, 1991).

In the cell, cholesterol is used as part of the cell membrane, either for the renewal of the existing membrane or for the synthesis of new membranes during cell division. However, if the demand for cholesterol decreases, the excess cholesterol is converted to cholesterol esters, bile acids, steroid hormones, lipoproteins, or is transported to other cells (Dinh, 2010).

In addition, cholesterol is a reactive molecule that can suffer oxidation reactions, producing COPs or oxysterols. The COPs have received considerable attention in recent years due to their biological activities associated with human diseases.

In this review, we discuss the synthesis of oxysterols during the oxidation of cholesterol and the factors influenc- $\overline{\text { Department of Veterinary Science, Laboratory of Environmental, }}$ Health and Animal Production, Institute of Veterinary Science and Agricultural Science, Batna University, 05000, Algeria

Corresponding Author: Hafid Nadia, Department of Veterinary Science, Batna University, 05000, Algeria., Email: nadvet@yahoo.fr; nadia.hafid@univ-batna.dz

How to cite this article: Nadia, H. (2019). COPs in Ruminant Meat: A Biological and Pathological Approach: A Review. Asian Journal Of Dairy and Food Research, 38(3): 191-202.

Source of support: Nil.

Conflict of interest: None

Submitted:05-07-2019 Accepted:20-09-2019 Published: 22-10-2019

ing the formation of COPs in meat such as the heat, the packing condition, $\mathrm{pH}$,

Finally, we present also the COPs metabolic pathways (absorption, elimination), and their most important biological activities and their impact on human health.

\section{Formation of COPs}

COPs, or oxysterols, are a family of 27-carbon oxidation derivatives of cholesterol (from a biological source) that can originate exogenously, such as from the diet, or endogenously. Oxysterols are structurally identical to cholesterol, but have one or more additional oxygencontaining functional groups, such as alcohol, carbonyl, or epoxide (Brown and Jessup, 2009).

\section{Cholesterol oxidation}

Cholesterol oxidation products (COPs) can be formed by non-enzymatic oxidation (autoxidation) or enzymatic reactions (Leonarduzzi et al., 2002; Smith and Murphy, 2008), as illustrated in Figure 1. Non-enzymatic oxidation affects the sterol ring, while enzymatic processes affect the side-chain of 


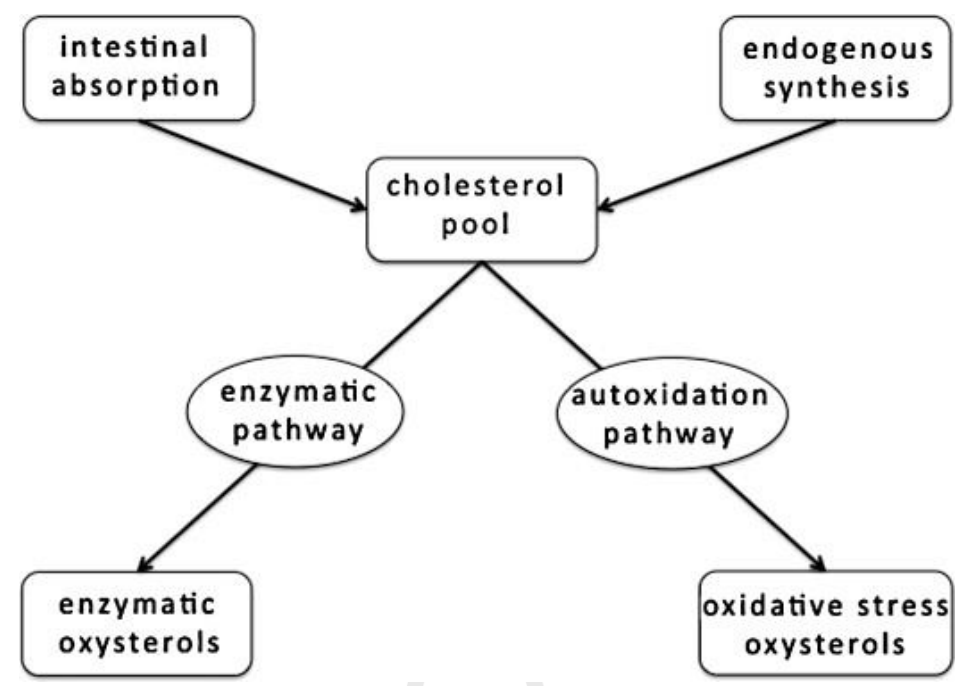

Figure 1 : Pathways of cholesterol oxidation (Iuliano, 2011)

sterol structures (Ryan et al., 2005). Oxidation can occur on the sterol nucleus, in particular in positions 4, 5, 6 and 7, which are the most sensitive to oxidation. It can also occur in positions 24,25 and 27 of the side chain. This leads to a large diversity of molecules, thus creating the family of oxysterols (Souidi et al., 2004). The cholesterol oxidation rate can be $57-68 \%$ of the initial concentration (Otaegui-Arrazola et al., 2010).

\section{Autoxidation}

By definition, autoxidation is a spontaneous reaction of molecular oxygen with lipids, leading to oxidative deterioration (Wasowicz et al.,2004). It includes free radical-, lipid peroxide-and divalent cation-induced oxidative processes.

In a membrane environment, cholesterol is more easily attacked than polyunsaturated fatty acids (PUFAs) by reactive oxygen species (ROS). Cholesterol autoxidation frequently starts at the methylene group in the allylic position (C-7) by a free radical, producing a cholesteryl radical that reacts rapidly with dioxygen to produce a $7 a$ - or $7 \beta$-peroxyl radical. The formed radical stabilizes, abstracts a hydrogen from the allylic carbon of another lipid molecule, and forms primary COPs-isomers of 7-hydroperoxycholesterol. The seven hydroperoxycholesterols can further convert into $7 \mathrm{a}$-hydroxycholesterol (7a-OHCh) and $7 \beta$-hydroxycholesterol (7ß-OHCh (Papuc et al., 2017).

The main products of cholesterol autoxidation present in muscle tissue are 7-ketocholesterol (7-keto), 20a-hydroxycholesterol, 25-hydroxycholesterol (25-OHCh) and a, $\beta$-epoxycholesterol (Orczewska-Dudek et al., 2012). Figure 2 shows the structure of cholesterol and the main autoxidation products present in food muscle tissue. The oxysterols contained in cholesterol-rich foods such as meat, meat products, eggs, and dairy products are most likely generated through a non-enzymatic process during cooking, processing, and storage (Brown and Jessup, 2009).

\section{Enzymatic oxidation of cholesterol}

The enzymatic oxidation of cholesterol is performed by several enzymes that are mainly from the cytochrome P450

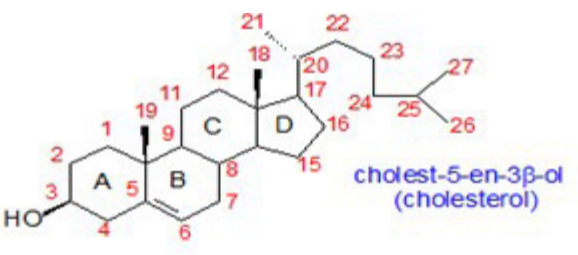

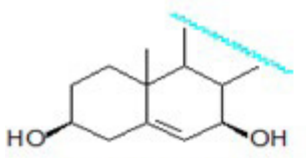

$7 \beta$-hydroxycholesterol

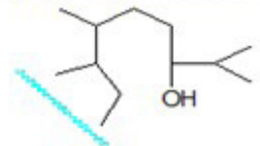

24-hydroxycholestero

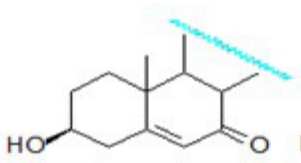

7-ketocholesterol

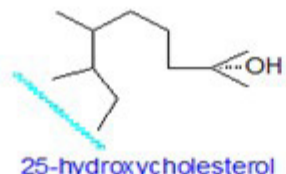

25-hydroxycholesterol

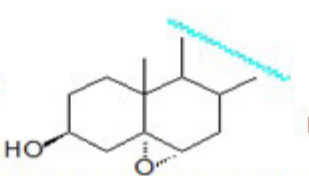

cholesterol-5c,6c-epoxide

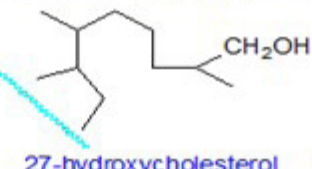

27-hydroxycholesterol

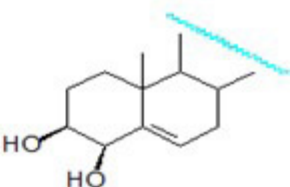

$4 \beta$-hydroxycholesterol

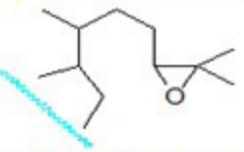

24,25-epoxycholesterol

Figure 2: Non-enzymatic oxidation products of cholesterol 
family of oxygenases, such as monooxygenase, dioxygenase, dehydrogenase, and oxidase. Enzymatic oxidation begins with the formation of specific hydroxycholesterol $(\mathrm{OHCh})$ molecules, as shown in Table 1.

Because certain enzymes are specific to particular tissues, there is considerable variation in oxysterol distribution across organs. For example, a primary product of enzymatic oxidation is $7 \mathrm{a}-\mathrm{OHCh}$, which is an important intermediate in the biosynthesis of bile acids and is produced in the liver by the action of cholesterol 7a-hydroxylase (CYP7A1), which has a critical role in cholesterol homeostasis (Gill et al.,2008). However, it is also formed by the non-enzymatic oxidation of cholesterol (Niki et al.,2005). The enzymatic reaction is under strict regulatory control, and any circulating $7 \mathrm{a}-\mathrm{OHCh}$ represents leakage from the liver.

In contrast, $7 \beta-\mathrm{OHCh}$ is produced in the brain by the action of the toxic $\beta$-amyloid peptide and its precursor to cholesterol. 24(S)-OHCh, termed cerebrosterol, is formed exclusively in the brain in humans, and there is a continuous flux of it from the brain to the circulation (Zhang and Liu, 2015). 22-OHCh is found preferentially in steroidogenic tissues, and $27-\mathrm{OHCh}$ in macrophages and plasma (Alioui, 2016).

The free radical-mediated oxidation of cholesterol results in $7 a-$ and $7 \beta$ - hydroperoxycholesterol $(7 a-O O H C h$ and $7 \beta-\mathrm{OOHCh}$ ), $7 \mathrm{a}-\mathrm{OHCh}, 7 \beta-\mathrm{OHCh}, 5 a, 6 a-$ and $5 \beta$, $6 \beta$-epoxycholesterol, and 7-keto as the major products (Diczfalusy, 2004). Side-chain oxidation products such as 20-, 22-, 24-, 25- and 27-OHCh are formed by an enzymatic mechanism.

The conversion of 7-keto to $7 \beta-\mathrm{OHCh}$ in vivo has been reported. The oxidation of $7-\mathrm{OHCh}$ either by the $7 \mathrm{a}-\mathrm{OHCh}$ dehydrogenase enzyme or by non-enzymatic autoxidation produces 7- Keto. Singlet oxygen oxidizes cholesterol by a non-enzymatic and non-radical mechanism to produce $5 \mathrm{a}-\mathrm{OHCh}$, with a lower quantity of $6-\mathrm{OHCh} .5-\mathrm{OHCh}$ is a specific marker for singlet oxygen oxidation. $7 \beta-\mathrm{OHCh}$ can be considered a marker for free radical-mediated oxidation (Niki et al., 2005).

\section{Photooxidation of cholesterol}

In addition to the free radical mechanism, there is another mechanism of oxidation that occurs in the presence of a sensitizer and UV-light and leads to the formation of hydroperoxides (Wasowicz et al., 2004). In the photooxidation of cholesterol, single oxygen is formed from triplet oxygen by light in the presence of an active sensitizer, such as a natural pigment or synthetic colorant. Cholesterol can react with singlet oxygen in the presence of a photosensitizer, forming dominant hydroperoxide at C-5. A part of the hydroperoxide converts into $5 \mathrm{a}-\mathrm{OHCh}$, and the remainder of the 5-hydroperoxide is further converted into stable 7-hydroperoxide and 6-hydroperoxide, which are present in small amounts. The 7-hydroperoxides can be converted into isomeric $7-\mathrm{OHCh}$ and 7-keto at the same time as $5-\mathrm{OHCh}$ is formed (Ubhayasekera, 2004).

\section{COPS IN RUMINANT MEAT}

The exogenous source of oxysterols is dietary intake (Otaegui-Arrazola et al., 2010). After slaughter, meat tissues lose their antioxidant defenses, and more complex oxidative processes emerge (Papuc et al., 2017) and promote the formation of oxidized sterols. Oxysterols absorbed from food have been shown to enter circulation (Brown and Jessup, 1999). However, an exact quantitative estimation of the levels of endogenous as opposed to exogenous oxysterols does not exist.

In lean meat, the mean lipid content is $10 \%$ of the weight, of which cholesterol is a small component, ranging from 50-89 mg (Paniangvait et al., 1995) and assumed to be less than $100 \mathrm{mg} / \mathrm{kg}$ (Ahn et al., 2001).

A number of studies have studied the oxidation of lipids in different types of meat. However, the majority of these studies did not consider the COP content of meat from ruminant species; instead, they considered non-ruminant species, such as turkey (Boselli et al., 2005), poultry (Bonoli et al., 2007) and pork (Rudzińska et al., 2007; Thurner et al., 2007). Several studies have considered the cholesterol oxidation of meat from ruminants, primarily beef (Verleyen et al., 2003; Thurner et al., 2007), and very few studies have considered lamb (Serra et al., 2006; Samouris et al., 2011). No studies have been conducted on COPs in raw goat meat, most likely because of this meat's low intramuscular cholesterol content relative to the meat of other ruminants.

Fresh meat and meat products contain zero or trace amounts of cholesterol oxides; in cooked meat; however, the oxysterol content ranges from 180 to $1900 \mu \mathrm{g} / \mathrm{g}$. The predominant oxidized cholesterol detected in ruminant meat is 7-ketocholesterol and 7-OHCh, followed by

Table 1: Enzymatic oxidation of cholesterol (Niki et al., 2005)

\begin{tabular}{lll}
\hline Enzyme & Abbreviation & Principal product \\
\hline Cytochrome P450 3A4 & CYP3A4 & $43-\mathrm{OHCh}$ \\
Cholesterol 7a -hydroxylase & CYP7A1 & $7 \mathrm{a}-\mathrm{OHCh}$ \\
Cytochrome P450 scc & CYP11A1 & $20 \mathrm{a}-\mathrm{OHCh}$, \\
Cholesterol 24-hydroxylase & CYP46 & $22-\mathrm{OHCh}$ \\
Cholesterol 25-hydroxylase & & $24(\mathrm{~S})-\mathrm{OHCh}$ \\
Sterol 27-hydroxylase & CYP27A1 & $25-\mathrm{OHCh}$ \\
& & $27-\mathrm{OHCh}$ \\
\hline
\end{tabular}


$\beta$-epoxycholesterol, a-epoxycholesterol, and cholestantriol (Hur et al., 2007; Serra et al., 2014). 7-keto occurs in relatively high concentrations in many foods (Pie et al., 1991) and its amount varies depending on the type of biological matrix (Lercker and Rodriguez-Estrada, 2000). It has also been proposed as an indicator of cholesterol oxidation (Shazamawati et al., 2013).

Lipid oxidation has been associated with quality deterioration related to the development of off-flavors and off-odors during storage (Kumar and Singhal, 1992). The excessive oxidation of cholesterol, however, affects the nutritional quality due to the implications of COPs in the modulation of lipid metabolic processes, such as linoleic acid desaturation and cholesterol metabolism (Boselli et al., 2012). Moreover, unlike the oxidation products of PUFAs, COPs are not volatile compounds; as a result, cholesterol oxidation cannot be identified by foul-smelling compounds (Dutta, 2004).

\section{Factors influencing OXYSTEROL CONCENTRATIONS IN MEAT}

The oxidation of cholesterol in muscle meat is influenced by many factors, such as the processing temperature for heating and cooking, storage time, packaging conditions, (Paniangvait et al., 1995), $\mathrm{pH}$, illumination and irradiation (Boselli et al., 2012). The oxysterols contained in cholesterolrich foods such as meat, meat products, eggs, and dairy products are most likely generated in a nonenzymatic way during cooking, processing, and storage (Brown and Jessup, 2009). The factors influencing the oxidation of cholesterol are discussed below.

\section{Heat}

The main source of oxysterols in meat is heat processing, mainly overheating (Paniangvait et al., 1995). Microwaving and oven grilling results in higher production of COPs in processed meat in comparison to other cooking methods (Khan et al., 2015). Several studies have been devoted to this subject. Lee et al. (2001) studied the effects of various cooking and reheating methods on the total cholesterol and formation of COPs in beef loin, and observed a significant reduction in cholesterol and an increase in COPs.

In addition, Dominguez et al. (2014) have reported that among various methods used for cooking foal meat, such as roasting, grilling, microwaving, and frying, microwaving produced the highest oxidation products. In addition, chicken and beef samples treated in the microwave $(900 \mathrm{~W}-3$ minutes; internal temperature of the samples at the end of the process: $\left.100^{\circ} \mathrm{C}\right)$ formed more COPs than those fried in olive oil $\left(180^{\circ} \mathrm{C}-6\right.$ minutes; internal temperature: $85-90^{\circ} \mathrm{C}$ ) (Echarte et al., 2003). Additionally, under drastic heating conditions such as $180^{\circ} \mathrm{C}$ for two hours in the presence of oxygen, there is a very high level of oxidation (Xu et al., 2009).

Table 2 illustrates the effects of different cooking methods on cholesterol oxidation in beef hamburgers, demonstrating a higher content of 7-keto from the combination of roasting and microwave heating in comparison to other cooking treatments.

\section{Storage and packaging}

Additional studies have reported an increase in COP formation during storage. Hwang and Maerker (1993) reported that storing non-irradiated beef at $0-4^{\circ} \mathrm{C}$ for two weeks considerably increased the COP content. Bendeddouche et al. (2012) observed the same result when storing raw lamb longissimus dorsi muscle under refrigeration for 20 days. Lee et al. (2006) observed an increase in COP formation after cooking stored beef loin. The results indicate that even frozen storage of cooked meat does not prevent the development of COPs. Furthermore, Ferioli et al. (2008) reported that the COP content in raw and cooked minced beef increased sixfold after storage at $4^{\circ} \mathrm{C}$ for two weeks, with the COP content higher in cooked meat than in raw meat.

With respect to the effects of packaging, researchers have reported the presence of COPs in fresh meat and have suggested that the transparent films used in packaging meat do not prevent cholesterol oxidation because they are permeable to light and oxygen, and the cholesterol oxidation process in meat is promoted by hem protein photocatalysis (Lercker and Rodriguez-Estrada 2000). Lee et al. (2001) have also suggested that the vacuum storage of cooked meat products promotes increased COP formation post-storage.

\section{$\mathrm{pH}$}

$\mathrm{pH}$ also affects the rate and abundance of COP formation. At a pH between 8.0 and 12.0, the production of $\mathrm{a}-$ and

Table 2: Effect of cooking treatments on the total 7-keto content and the ratio of total 7-keto to total cholesterol (Savage et al., 2007)

\begin{tabular}{lll}
\hline Treatment & 7 -keto $(\mu \mathrm{g} / \mathrm{g}$ in lipids)* & 7-keto/total cholesterol (\%)* \\
\hline Raw & $25.2 \mathrm{~d}$ & $0.5 \mathrm{~b}$ \\
Roasted & $18.0 \mathrm{~b}$ & $0.5 \mathrm{~b}$ \\
Microwave & $19.6 \mathrm{c}$ & $0.4 \mathrm{a}$ \\
Microwave and roasted & $22.0 \mathrm{e}$ & $0.5 \mathrm{~b}$ \\
Barbecue & $19.5 \mathrm{c}$ & $0.4 \mathrm{a}$ \\
Boiling & $16.4 \mathrm{a}$ & $0.4 \mathrm{a}$ \\
Frying pan & $18.6 \mathrm{~b}$ & $0.4 \mathrm{a}$ \\
\hline
\end{tabular}

*Mean values of three replications. (a_e): Means with different superscripts within the same category are significantly different $(p=0.05)$. 
$\beta$-cholesterol epoxide is time-dependent with a ratio that is approximately constant. However, at $\mathrm{pH}$ between 5.5 and 3.0 , this ratio progressively increases, since the $\beta$-isomer is more labile in acidic conditions than the $a$-isomer, being preferentially converted to cholesterol by hydrolysis (Vicente et al., 2012).

\section{Illumination}

Various COPs are formed through the oxidation of cholesterol during illumination, and their quantity increases with an increased illumination time. In addition, COPs are more concentrated at the surface of the meat than throughout the rest of it during illumination. The COPs produced include free radicals formed by triplet sensitizer-reducing substrate interaction (Hwang and Maerker, 1993).

\section{Irradiation}

Hwang and Maerker (1993) have reported that the irradiation of raw beef and veal at ten kGy increased the COP content, and the increase in COPs in those meats during storage was greater in the irradiated meat than the non-irradiated meat. The same results have been reported for other meat species (Ahn et al., 2001; Lee et al., 2001).

The effects of storage and radiation have also been noted in some studies, in which COPs such as 7a-OHCh, $7 \beta-\mathrm{OHCh}$, and 7-keto were detected in fresh raw meats at day zero at a level of 10.9 to $49.2 \mathrm{mg} / \mathrm{g}$ lipid. After seven days of storage, other COPs, such as epoxides, 20a-OHCh and cholestanetriol, were formed in mainly aerobically packaged and irradiated raw meats (Nam et al., 2001).

\section{Lipid content and composition}

The composition and content of fats in meat play an important role in the oxidation rates of lipids and cholesterol (Ahn et al., 2001). As a general rule, the more unsaturated a fatty acid is, the faster and more intense the formation of COPs is (Vicente et al., 2012). For example, Li et al. (1996) and Min et al. (2015) have reported that a high level of PUFAs leads to increased production of COPs. In addition, the synergistic decrease in the levels of cholesterol, and PUFAs provides evidence that cholesterol oxidation is promoted by the oxidation of PUFAs.

PUFA content varies considerably across animal species and decreases in the following order: fish $>$ poultry $>$ pork $>$ beef $>$ lamb. Therefore, the susceptibility to lipid oxidation and the consequent formation of COPs decreases in the same order (Hur et al., 2007).

The environmental conditions promoting the production of COPs have not yet been determined. However, it is reasonable to suspect that the oxidation of cholesterol is accelerated in the presence of peroxidized lipids (Li et al., 1996). Xu et al. (2011) have investigated the interactions of stearic, oleic, linoleic, and a-linolenic acids during the oxidation of cholesterol, and concluded that surrounding fatty acids affect cholesterol oxidation. They also reported that the fatty acids accelerated the oxidation of cholesterol for the first 60 minutes at $180^{\circ} \mathrm{C}$, after which their pro-oxidant activity became weaker, with the exception of a-linolenic acid, which exerted an inhibitory effect after 120 minutes.

\section{Sex}

Sex has not been widely considered a variable in food research, although the effect of sex on meat composition has occasionally been reported. For example, in a recent study conducted by Vladimiro et al. (2016) on eight Segureña lambs, samples of approximately $20 \mathrm{~g}$ of minced meat from lamb leg were used for cooking burger patties at $72^{\circ} \mathrm{C}$. With the exception of $7 \mathrm{a}-\mathrm{OHCh}$, male meat samples were characterized by high COP contents in comparison to female meat samples.

\section{Age}

Serra et al. (2014) reported that the cholesterol content of lamb muscles tended to decrease with the age of an animal, while the COP content significantly increased. Among COPs, 7-ketocholesterol and 7-OHCh were the most abundant, followed by epoxy-cholesterol and cholestane-triol.

\section{Metabolism of COPs}

Cholesterol oxidation products (COPs), or oxysterols, tend to be more polar than cholesterol and can be absorbed in the human intestinal tract and distributed to tissues by a mechanism similar to that of cholesterol absorption. The absorption of COPs is lower than that of cholesterol, likely due to the lower solubility of COPs in micelles, the lower susceptibility to esterification in enterocytes, and the cytotoxic effects in mucosal cells (Osada et al., 1994). In addition, each type of COP is absorbed to different degrees; $7 \beta-\mathrm{OHCh}, 7-k e t o$, and 5a, 6a-epoxycholesterol are detected in greater amounts than $5 \beta, 6 \beta$-epoxycholesterol, and $25-\mathrm{OHCh}$ (Vine et al., 1998). Notably, in contrast to $7 \beta-\mathrm{OHCh}$, 7-keto is slightly absorbed and rapidly metabolized by the liver (Schweizer et al., 2004).

Oxysterols are able to pass through lipophilic membranes much faster than cholesterol (Linseisen and Wolfram, 1998). They can enter the blood circulation with dietary cholesterol and biliary cholesterol (endogenous cholesterol) as part of the chylomicron structure (Savage et al., 2002; Shazamawati et al., 2013) and lipoprotein, primarily low density lipoprotein (LDL) and, to a lesser degree, high density lipoprotein (HDL) (Staprans et al., 2003). 7a/ $\beta$ - OHCh and 7-keto are the most abundant oxysterols in lipoproteins (Linseisen and Wolfram, 1998; Vine et al., 1998). Recent studies have shown that unesterified cholesterol oxides associate readily with serum albumin (Lin and Morel, 1995).

Due to their hydrophobicity, most oxysterols can only be eliminated from cells through specific membrane lipid transporters. Apart from the ATP-binding cassette $(A B C)$ transporters, $A B C G 5$ and $A B C G 8$, which pump oxysterols back into the intestine, there are other ATP-binding cassette transporters involved in oxysterol excretion. ABCA1 and $A B C G 1$ are mainly located in the macrophages and liver to 
transport oxidized sterols and other molecules out of the cell (Brown and Jessup, 2009).

\section{The BIOLOGICAL EFFECT OF COPS}

In the following section, the major biological roles of oxysterols are discussed, and other roles are summarised in Figure 3.

\section{Oxysterol as a cholesterol modulator (metabolism and homeostasis)}

Several oxysterols enzymatically generated from cholesterol are able to regulate the intracellular cholesterol content through the following mechanisms.

\section{Sterol regulatory element binding proteins SREBPS}

Oxysterols have been described as modulators of cholesterol metabolism through their influence on the sequestration of SREBPs in the endoplasmic reticulum (ER), thereby limiting the expression of genes involved in cholesterol synthesis. The insulin-induced gene (Insig), an oxysterol sensor, is another key regulator in the ER membrane. It can inhibit the function of the SREBP by trapping and retaining the SREBP cleavage activating protein (SCAP) complex in the ER. Thus, several oxysterols such as 22(R)-OHCh, 25-OHCh and 24(S), 25-epoxycholesterol are able to attenuate cholesterol biosynthesis and the expression and activity of the LDL receptor in a macrophage (Shao and Espenshade 2012).

Oxysterol binding protein (OSBP)/OSBP-related proteins (ORP)

Oxysterols can also control the esterification of cholesterol and the activity of hydroxymethylglutaryl-CoA reductase (HMG-CoA), the rate-limiting enzyme in cholesterol synthesis (Brown and Jessup, 2009), through the OSBP) and ORP (Kentala et al., 2015). In the human body, there are at least 12 OSBP/ORP proteins. OSBP, ORP1, and ORP2 are involved mainly in vesicle transport of cholesterol, particularly the transport between the ER and Golgi apparatus (Olkkonen, 2015).

liver $\mathrm{X}$ receptor $(L X R)$

Oxysterols also have ligands of the nuclear LXR, whose essential role in the maintenance of cholesterol homeostasis, thus protecting cells from the toxic effects of cell cholesterol overload. The LXR regulates the expression of the proteins involved in the efflux and transport of cholesterol. The most potent of these oxysterol ligands are 22(R)- $\mathrm{OHCh}, 24(\mathrm{~S})-\mathrm{OHCh}$ and 24(S), 25-epoxycholesterol (Kuver, 2012).

\section{Oxysterols in immune cell function}

Oxysterols, acting through transcription factors such as LXRs, SREBPs and the Epstein-Barr virus-induced G-protein coupled receptor 2 (EBI2), have been implicated in regulating the differentiation and population expansion of cells of the innate and adaptive immune systems, their responses to inflammatory mediators. They have also been implicated in phagocytic functions of macrophages and in antiviral activities and immune cell migration (Spann and Glass, 2013). For example, the 7a, 25-dihydroxycholesterol oxysterol is a potent and selective agonist of the G-protein-coupled receptor EBI2, which is required for humoral immune responses (Hannedouche et al., 2011).

\section{Oxysterols as developmental process regulators}

The Hedgehog $(\mathrm{Hh})$ signaling pathway is indispensable for normal patterning of multicellular embryos and also functions in postembryonic development and adult tissue homeostasis, including the regulation of stem cell physiology (Jacob and Lum, 2007). Corcoran and Scott (2006) have

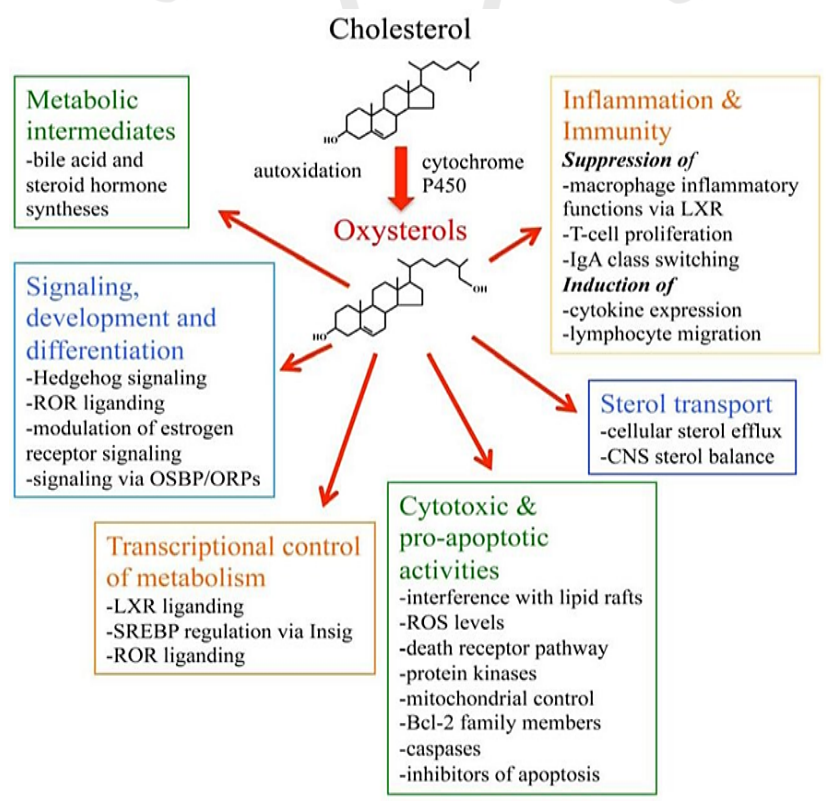

ROR, retinoic acid receptor-related orphan receptor; Bcl-2, B-cell lymphoma 2; IgA, immunoglobulin A; CNS, central nervous system.

Figure 3: Schematic diagram summarising the major functions of oxysterols

(Olkkonen et al., 2012) 
reported evidence that cholesterol or certain oxysterols are required for Sonic Hh pathway signal transduction and proliferation of medulloblastoma cells. Additionally, Dwyer et al., (2007) have demonstrated that naturally occurring oxysterols exert osteoinductive effects through the activation of the Hh signaling pathway. Similarly, Kim et al. (2007) have provided evidence that the inhibition of bone marrow stromal cell differentiation into adipocytes by $20(\mathrm{~S})-\mathrm{OHCh}$ occurs through an $\mathrm{Hh}$-dependent mechanism.

\section{Oxysterols as oestrogen receptor function regulators}

Oestrogen receptor- $\alpha / \beta(E R-\alpha / \beta)$ is a member of a nuclear hormone superfamily, and mediates a number of physiological processes. Oestrogens exert protective effects on the blood vessel wall, regulating the cardiovascular system. $27-\mathrm{OHCh}$ has been found to directly antagonize the transcriptional and non-transcriptional functions of the oestrogen receptors, resulting in a loss of the cardioprotective function of oestrogen. This oxysterol thus acts as an endogenous selective oestrogen receptor modulator based on its celltype-specific proestrogenic activity (Chen, 2016).

\section{Oxysterols as pro-apoptotic and cytotoxic factors}

Apoptosis is genetically programmed cell death that has been conserved throughout evolution and used to maintain normal cell numbers in the organism, including during growth. It is a coordinated and active process characterized by specific morphological changes: chromatin condensation and nuclear fragmentation, membrane blebbing, and apoptotic body formation. Apoptosis is triggered through both an extrinsic, or death-receptor-mediated, pathway and an intrinsic, or mitochondrial, pathway. Both pathways appear to be activated by a variety of biologically relevant oxysterols that exert strong pro-apoptotic effects. Some findings support the involvement of death receptors in oxysterolinduced apoptosis. 27-OHCh and 22-OHCh induce tumor necrosis factor-a (TNF-a) in macrophagic cells (Gargiulo et al., 2015), and upregulation of TNF receptors has been observed in human aortic smooth muscle cells after challenged with 7-keto (Lee et al., 2005).

With respect to cytotoxic activities, several routes have been proposed for COPs: perturbation of intracellular calcium levels, intracellular ROS overproduction, mitochondrial and lysosomal membrane modifications, and polyamine metabolic perturbations (Sottero et al., 2009).

\section{IMPACT OF COPS ON HUMAN HEALTH}

In recent years, considerable attention has been devoted to the study of cholesterol oxidation due to the biological activities of COPs associated with human diseases. Research has demonstrated that certain cholesterol oxides are cytotoxic, mutagenic, and carcinogenic (Otaegui Arrazola et al., 2010). Moreover, they slow down deoxyribonucleic acid (DNA) and cholesterol biosynthesis and are calmodulin inhibitors, disturbing the activity of cell membranes (Derewiaka and Obiedziński, 2009).

\section{Oxysterol and atherosclerosis}

Atherosclerosis is a progressive disease of the arterial blood vessels and a principle contributor to the pathogenesis of myocardial and cerebral infarction. As such, it is the leading cause of human mortality. Many studies have detected oxysterols in human atherosclerotic plaque, especially 27-OHCh. Following 27-OHCh, 7-keto is the most abundant oxysterol in advanced atherosclerotic lesions, followed by $7 \beta-\mathrm{OHCh}$ and $7 \mathrm{a}-\mathrm{OHCh}$ (luliano et al., 2003). Together, these four oxysterols comprise $75-85 \%$ of the nine oxysterols detected in plaques.

The other oxysterols are 5, 6-epoxycholesterol, 25-OHCh, and $24-\mathrm{OHCh}$. Although there is no direct evidence in humans that oxysterols contribute to the development of atherosclerosis, these oxysterols are thought to play an active role in plaque development due to their cytotoxicity (Shibata and Glass, 2010).

The most prevalent oxysterol in cardiovascular lesions is $27-\mathrm{OHCh}$, and it is considered a major factor responsible for triggering atherosclerosis (Dantas et al., 2015). Levels of circulating $27-\mathrm{OHCh}$ in health humans range from 150 to 730 $\mathrm{nM}$; in atherosclerotic lesions, these levels are two orders of magnitude higher (Brown and Jessup, 1999). Moreover, evidence suggests that $27-\mathrm{OHCh}$ promotes atherogenesis by upregulating the inflammatory pathways in vascular cells and increasing the accumulation of macrophages in the vascular wall (Kloudova et al., 2017).

Another oxysterol, 7-keto, is one of the major oxygenated products found in oxidised low-density lipoproteins (oxLDLs) and in atherosclerotic plaque, where it is believed to play a role in arterial pathology (Philips et al., 2001). It is also involved in atherosclerosis development, either by inducing apoptosis or by inhibiting reverse cholesterol transport (Sozen et al., 2018). Levels of 7-keto are considerably increased in the plasma of patients with coronary artery disease (Pordal et al., 2015).

Oxysterols, as quantitatively relevant components of oxLDLs, are likely to be candidate molecules in the pathogenesis of vascular aging (Kloudova et al., 2017). They accumulate in the endothelium blood vessels, constituting one of the most important elements of atheroma (Jailal and Devaraj, 1996) due to their marked pro-oxidant, proinflammatory, and pro-apoptotic properties. They are also implicated in the age-related genesis of endothelium dysfunction, intimal thickening due to lipid accumulation and smooth muscle cell migration, and arterial stiffness due to increased collagen deposition and calcification (Gargiulo et al., 2016), as shown in Figure 4.

\section{Oxysterol and neurodegenerative disorders}

Oxysterols also present interesting targets in various neurodegenerative disorders, such as multiple sclerosis, Huntington's disease, Parkinson's disease and Alzheimer's disease (Kulig et al., 2016), specifically in the form of 24-OHCh, or cerebrosterol. Therefore, $24 \mathrm{~S}-\mathrm{OHCh}$ plasma levels can 


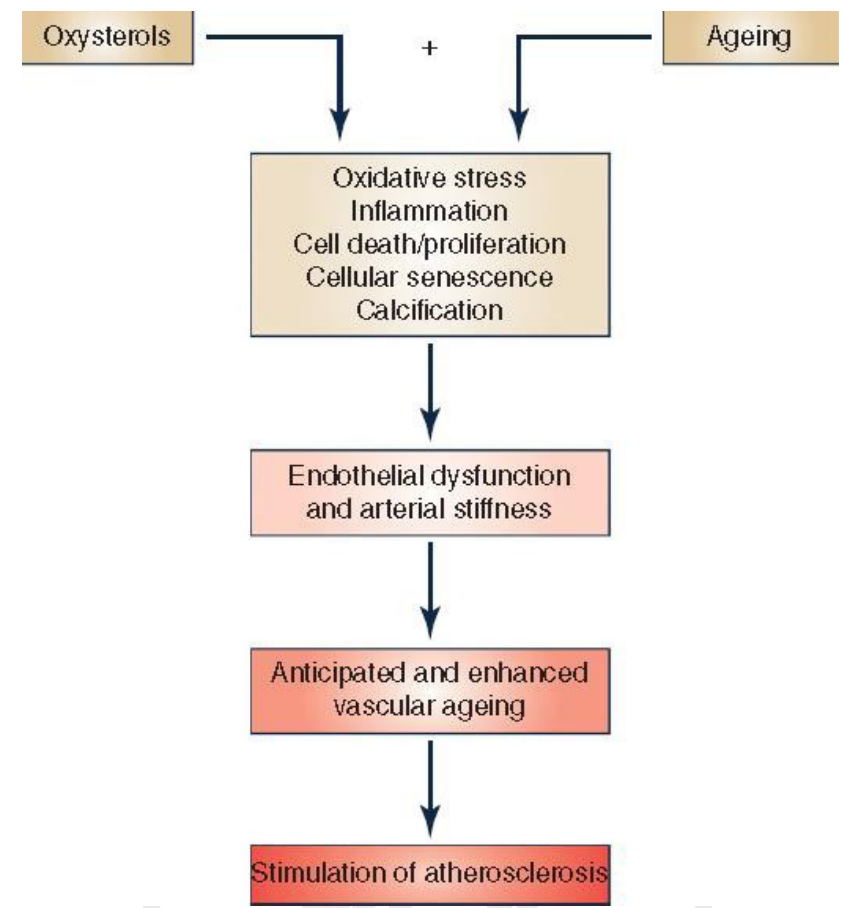

Figure 4: Role of oxysterols in atherosclerosis and vascular ageing (Gargiulo et al., 2016)

potentially be used as an early biochemical marker for altered cholesterol homeostasis in the central nervous system (Lütjohann et al., 2000). Another study has reported that 24-OHCh in concentrations of 10-50 $\mu \mathrm{M}$ induces apoptosis in T-lymphoma Jurkat cells and necroptosis in neuronal cells (Yamanaka et al., 2015).

For example, Alzheimer's disease, the most common cause of dementia in the elderly, is characterized by a regional accumulation of senile plaques, neurofibrillary tangles, and extensive neuronal cell death. 24S-OHCh may be a major component of the mechanism that promotes the elimination of cerebral cholesterol (Lutjohann et al., 2000); however, in too large of a quantity, it can be neurotoxic. An increase in the concentration of $24 \mathrm{~S}-\mathrm{OHCh}$ can be due to mutations in the gene coding for the enzyme that synthesizes it in the brain, CYP46A1 (Kolsch et al., 2002). 24S-OHCh is one of the ligands of LXRs. At the cerebral level, this may explain the induction of target genes such as ABCA1, a membrane transporter involved in the cellular efflux of cholesterol that appears also to be involved in the secretion of beta peptidesprotein constituents of senile plaques in Alzheimer's disease (Fukumoto et al., 2002).

\section{Oxysterol and cancer}

The 27-OHCh oxysterol is the most abundant oxysterol in plasma, and its involvement has been demonstrated in the pathogenesis of several cancers, including breast and prostate cancer. For example, in breast cancer, oxysterols are important navigators that stimulate bone metastasis formation (Silva et al., 2006). 27-OHCh has been found to accumulate in breast tissue and stimulate tumor growth via the oestrogen receptor. Although most tissues express CYP27A1, its highest levels are in macrophages. Therefore, more attention has been given to the production of $27-\mathrm{OHCh}$ in subendothelial macrophages as part of reverse cholesterol transport (Javitt, 2015).

In men, 27-OHCh may influence prostate carcinoma by stimulating the proliferation of prostatic cells, enhancing the expression of prostate-specific antigen, and increasing androgen receptor transcriptional activity (Raza et al., 2016). However, its role in colorectal cancer has not been investigated. Warns et al. (2018) treated Caco2 and SW620, two well-characterized colon cancer cells, with low, physiological, and high concentrations of $27-\mathrm{OHCh}$, and found that $27-\mathrm{OHCh}$ reduced cellular proliferation in these cells.

\section{Conclusion}

Cholesterol oxidation products (COPs) have crucial physiological functions, serving as metabolic intermediates, modulators of cell permeability, and regulators of cholesterol homeostasis and the expression of genes and receptors in cell signaling. Elucidating the role of oxysterol interactions with human receptors, such as oestrogen receptors and Insig, has opened new avenues for better understanding lipid metabolism, Alzheimer's disease, cancer, atherosclerosis, and other pathologies.

Additional studies on oxysterols are needed to facilitate the diagnosis, treatment, and prevention of these disorders. These studies should use genomic, proteomic, and metabolomic profiling of a series of blood samples and target tissues from patients with different pathologies. In addition, further research is needed to determine the most effective way to apply antioxidants to prevent the oxidation of cholesterol. This task is a challenge for biochemists, food chemists, food engineering engineers, and processing technologists. 


\section{References}

Ahn, D. U., Nam, K. C., Du, M., et al., (2001). Effect of irradiation and packaging conditions after cooking on the formation of cholesterol and lipid oxidation products in meats during storage. Meat Science, 57(4): 413-418. doi: 10.1016/S03091740(00)00119-4

Alioui, A. (2016). Rôle des récepteurs aux oxystérols LXRs (Liver X Receptors) dans la dissémination métastatique du cancer de la prostate. Doctoral dissertation, Université Blaise PascalClermont-Ferrand II, 449p.

Bendeddouche, B., Bensid, A., Houicher, A., and Bendeddouche, E. (2012). Conservation de la viande d'agneau. Viandes et Produits Carnés, 9.

Bonnet, M.; Gruffat, D. and Hocquette, J.-F. (2010). Métabolisme lipidique des tissus musculaires et adipeux. In : Quae (Eds), Muscle et viande de ruminant, (81-90p).

Bonoli, M., Caboni, M. F., Rodriguez-Estrada, M. T., and Lercker, G. (2007). Effect of feeding fat sources on the quality and composition of lipids of precooked ready-to-eat fried chicken patties. Food Chemistry, 101(4): 1327-1337. doi: 10.1016/j. foodchem.2006.03.038

Boselli, E., Caboni, M. F., Rodriguez-Estrada, M.T., Toschi, T. G., Daniel, M., and Lercker, G. (2005). Photooxidation of cholesterol and lipids of turkey meat during storage under commercial retail conditions. Food Chemistry, 91(4): 705-713. doi: 10.1016/j. foodchem. 2004.06.043

Boselli, E., Cardenia, V., and Rodriguez-Estrada, M. T. (2012). Cholesterol photosensitized oxidation in muscle foods. European Journal of Lipid Science and Technology, 114(6):644-655. doi:10.1002/ ejlt.201100352

Brown, A. J., and Jessup, W. (2009). Oxysterols: sources, cellular storage and metabolism, and new insights into their roles in cholesterol homeostasis. Molecular aspects of medicine, 30 (3): 111-122. doi: 10.1016/j.mam.2009.02.005

Chen, Y. (2016). Characterization of oxysterols produced in macrophages and mechanisms of regulation. Doctoral dissertation, Université de Lyon. INSA, 140p.

Corcoran, R. B., and Scott, M. P. (2006). Oxysterols stimulate Sonic hedgehog signal transduction and proliferation of medulloblastoma cells. Proceedings of the National Academy of Sciences, 103(22): 8408-8413. doi:10.1073/pnas.0602852103

Cullis, P. R., and Hope, M. J. (1991). Physical properties and functional roles of lipids in membranes. New Comprehensive Biochemistry. 20:1-41. doi:10.1016/S0167-7306 (08)6032 9-4

Dantas, N. M., Sampaio, G. R., Ferreira, F. S., Labre, T. D. S., Torres, E. A. F. D. S., and Saldanha, T. (2015). Cholesterol oxidation in fish and fish products. Journal of Food Science, 80(12): R2627R2639. doi: 10.1111/1750-3841.13124

Derewiaka, D., and Obiedzinski, M. (2009). Oxysterol content in selected meats and meat products. Acta Scientiarum Polonorum. Technologia Alimentaria, 8(3).

Diczfalusy, U. (2004). Analysis of cholesterol oxidation products in biological samples. Journal of AOAC International, 87(2): 467-473.

Dinh, T. T. N. (2010). Development, validation, and application of cholesterol determination method for meat and poultry products using gas chromatography. Doctoral dissertation. Texas Tech University, 191p

Domínguez, R., Gómez, M., Fonseca, S., and Lorenzo, J. M. (2014). Effect of different cooking methods on lipid oxidation and formation of volatile compounds in foal meat. Meat Science, 97(2): 223-230. doi: 10.1016/j.meatsci.2014.01.023.

Dutta, P.C., (2004). Accurate and reproducible methods for analysis of sterol oxidation products in foods: an overview. Journal of the American Official Analytical Chemists International, 87: 439-440.

Dwyer, J. R., Sever, N., Carlson, M., Nelson, S. F., Beachy, P. A., and Parhami, F. (2007). Oxysterols are novel activators of the hedgehog signaling pathway in pluripotent mesenchymal cells. Journal of Biological Chemistry. 282(12): 8959-8968. doi: 10.1074/jbc. M611741200

Echarte, M., Ansorena, D., and Astiasarán, I. (2003). Consequences of microwave heating and frying on the lipid fraction of chicken and beef patties. Journal of Agricultural and Food Chemistry, 51(20): 5941-5945. doi: 10.1021/jf0345245

Evrat-Goergel, C. (2005). Etude préalable sur la construction d'une table de composition nutritionnelle des produits carnés (viande et abats de ruminants). Etude CIV OFIVAL, Institut de l'élevage.

Ferioli, F., Caboni, M. F., and Dutta, P. C. (2008). Evaluation of cholesterol and lipid oxidation in raw and cooked minced beef stored under oxygen-enriched atmosphere. Meat Science, 80(3): 681-685. doi: 10.1016/j.meatsci.2008.03.005.

Fukumoto, H., Deng, A., Irizarry, M. C., Fitzgerald, M. L., and Rebeck, G. W. (2002). Induction of the cholesterol transporter ABCA1 in CNS cells by LXR agonists increases secreted $A ß$ levels. Journal of Biological Chemistry. 277(50) : 48508-48513. doi : 10.1074/ jbc.M209085200

Gandemer, G. (1992). Les lipides de la viande : vers une estimation précise de leurs apports nutritionnels dans l'alimentation de I'homme. Cahiers de l'ENSBANA, 8: 25-48

Gargiulo, S., Gamba, P., Testa, G., Leonarduzzi, G., and Poli, G. (2016). The role of oxysterols in vascular ageing. The Journal of Physiology, 594(8): 2095-2113. doi: 10.1113/ JP271168

Gargiulo, S., Gamba, P., Testa, G., Rossin, D., Biasi, F., Poli, G., and Leonarduzzi, G. (2015). Relation between TLR4/NF-kB signaling pathway activation by 27-hydroxycholesterol and 4hydroxynonenal, and atherosclerotic plaque instability. Aging Cell, 14(4): 569-581. doi: 10.1111/acel.12322.

Gill, S., Chow, R., and Brown, A. J. (2008). Sterol regulators of cholesterol homeostasis and beyond: the oxysterol hypothesis revisited and revised. Progress in Lipid Research, 47(6): 391404. doi: 10.1016/j.plipres.2008.04.002.

Hannedouche, S., Zhang, J., Yi, T., Shen, W., Nguyen, D., Pereira, J. P., .., Knochenmuss, R. (2011). Oxysterols direct immune cell migration via EBI2. Nature, 475(7357): 524. doi: 10.1038/ nature10280.

Hur, S. J., Park, G. B., and Joo, S. T. (2007). Formation of cholesterol oxidation products (COPs) in animal products. Food Control, 18(8): 939-947. doi:10.1016/j.foodcont.2006.05. 008.

Hwang, K. T., and Maerker, G. (1993). Quantitation of cholesterol oxidation products in unirradiated and irradiated meats. 
Journal of American Oil Chemists' Society, 70(4): 371-375. doi: 10.1007/BF02552709

Iuliano L, Micheletta F, Natoli S, Ginanni Corradini S, lappelli M, Elisei W, Giovannelli L, Violi F, Diczfalusy U, (2003). Measurement of oxysterols and 16 tocopherol in plasma and tissue samples as indices of oxidant stress status. Anal Biochem, 312: 217-223. doi: 10.1016/S0003-2697(02)00467-0

Iuliano, L. (2011). Pathways of cholesterol oxidation via non-enzymatic mechanisms. Chemistry and Physics of Lipids, 164(6): 457-468. doi: 10.1016/j.chemphyslip.2011.06.006.

Jacob, L., and Lum, L. (2007). Deconstructing the hedgehog pathway in development and disease. Science, 318(5847): 66-68. doi: 10.1126/science.1147314

Jialal, I., and Devaraj, S. (1996). Low-density lipoprotein oxidation, antioxidants, and atherosclerosis: a clinical biochemistry perspective. Clinical Chemistry, 42(4): 498-506.

Javitt, N. B. (2015). Breast cancer and (25R)-26-hydroxycholesterol. Steroids. 104: 61-64. doi: 10.1016/j.steroids.2015.08.012.

Kentala, H., Pfisterer, S. G., Olkkonen, V. M., and Weber-Boyvat, M. (2015). Sterol liganding of OSBP-related proteins (ORPs) regulates the subcellular distribution of ORP-VAPA complexes and their impacts on organelle structure. Steroids, 99:248-258. doi: 10.1016/j.steroids.2015.01.027.

Khan, M. I., Min, J. S., Lee, S. O., Yim, D. G., Seol, K. H., Lee, M., and Jo, C. (2015). Cooking, storage, and reheating effect on the formation of cholesterol oxidation products in processed meat products. Lipids in Health and Disease, 14(1): 89. doi: 10.1186/s12944-015-0091-5.

Kim, W. K., Meliton, V., Amantea, C. M., Hahn, T. J., and Parhami, F. (2007). 20 (S)-hydroxycholesterol inhibits PPARy expression and adipogenic differentiation of bone marrow stromal cells through a hedgehog-dependent mechanism. Journal of Bone and Mineral Research, 22(11): 1711-1719. doi: 10.1359/ jbmr.070710

Kloudova, A., Guengerich, F. P., and Soucek, P. (2017). The role of oxysterols in human cancer. Trends in Endocrinology and Metabolism, 28(7): 485-496. doi: 10.1016/j.tem.2017.03 .002.

Kölsch, H., Lütjohann, D., Ludwig, M., Schulte, A., Ptok, U., Jessen, F., ..., Heun, R. (2002). Polymorphism in the cholesterol 24S-hydroxylase gene is associated with Alzheimer's disease. Molecular psychiatry, 7(8): 899. doi: 10.1038/ sj.mp.4001109

Kulig, W., Cwiklik, L., Jurkiewicz, P., Rog, T., and Vattulainen, I. (2016). Cholesterol oxidation products and their biological importance. Chemistry and Physics of Lipids, 199: 144-160. doi: 10.1016/j.chemphyslip.2016.03.001

Kumar, N., and Singhal, O. P. (1992). Effect of processing conditions on the oxidation of cholesterol in ghee. Journal of the Science of Food and Agriculture, 58(2): 267-273. doi: 10.1002/ jsfa.2740580216

Kuver, R. (2012). Mechanisms of oxysterol-induced disease: insights from the biliary system. Clinical Lipidology, 7(5):537-548. doi: 10.2217/clp.12.53

Lee, S. O., Lim, D. G., Seol, K. H., Erwanto, Y., and Lee, M. (2006). Effects of various cooking and re-heating methods on cholesterol oxidation products of beef loin. Asian Australasian Journal of Animal Sciences, 19(5): 756. doi: 10.5713/ajas.2006.756.
Lee, H. S., Chang, J. S., Baek, J. A., Chung, M. Y., Lee, H. C., Rhim, B. Y., ..., Kim, K. (2005). TNF-a activates death pathway in human aorta smooth muscle cell in the presence of 7-ketocholesterol. Biochemical and Biophysical Research Communications, 333(4): 1093-1099. doi:10.1016/j. bbrc.2005.05.196

Lee, J. I., Kang, S., Ahn, D. U., and Lee, M. (2001). Formation of cholesterol oxides in irradiated raw and cooked chicken meat during storage. Poultry Science, 80(1): 105-108. doi: 10.1093/ ps/80.1.105

Leonarduzzi, G., Sottero, B., and Poli, G. (2002). Oxidized products of cholesterol: dietary and metabolic origin, and proatherosclerotic effects. The Journal of Nutritional Biochemistry, 13(12): 700-710. doi: 10.1016/S09552863(02)00222-X

Lercker, G., and Rodriguez-Estrada, M. T. (2000). Cholesterol oxidation: presence of 7-ketocholesterol in different food products. Journal of Food Composition and Analysis, 13(4): 625-631. doi: 10.1006/jfca.2000.0901

Li, S. X., Cherian, G., Ahn, D. U., Hardin, R. T., and Sim, J. S. (1996). Storage, heating, and tocopherols affect cholesterol oxide formation in food oils. Journal of Agricultural and Food Chemistry, 44(12): 3830-3834. doi: 10.1021/jf9507320

Lin, C. Y., and Morel, D. W. (1995). Distribution of oxysterols in human serum: characterization of 25-hydroxycholesterol association with serum albumin. The Journal of Nutritional Biochemistry, 6(11): 618-625. doi: 10.1016/09552863(95)00122-G

Linseisen, J., and Wolfram, G. (1998). Absorption of cholesterol oxidation products from ordinary foodstuff in humans. Annals of Nutrition and Metabolism, 42(4): 221-230. doi: 10.1159/000012737

Lütjohann, D., Papassotiropoulos, A., Björkhem, I., Locatelli, S., Bagli, M., Oehring, R. D., ..., Heun, R. (2000). Plasma 24S-hydroxycholesterol (cerebrosterol) is increased in Alzheimer and vascular demented patients. Journal of Lipid Research, 41(2): 195-198.

Min, J. S., Lee, S. O., Khan, M. I., Yim, D. G., Seol, K. H., Lee, M., and Jo, C. (2015). Monitoring the formation of cholesterol oxidation products in model systems using response surface methodology. Lipids in Health and Disease, 14(1): 77. doi: 10.1186/s12944-015-0074-6.

Nam, K. C., Du, M., Jo, C., and Ahn, D. U. (2001). Cholesterol oxidation products in irradiated raw meat with different packaging and storage time. Meat Science, 58(4): 431-435. doi: 10.1016/ S0309-1740(01)00046-8

Niki, E., Yoshida, Y., Saito, Y., and Noguchi, N. (2005). Lipid peroxidation: mechanisms, inhibition, and biological effects. Biochemical and Biophysical Research Communications, 338(1): 668-676. doi:10.1016/j.bbrc.2005.08.072

Olkkonen, V. M. (2015). OSBP-related protein family in lipid transport over membrane contact sites. Lipid insights, 8: LPI-S31726. doi: 10.4137/LPI.S31726.

Olkkonen, V. M., Béaslas, O., and Nissilä, E. (2012). Oxysterols and their cellular effectors. Biomolecules, 2(1): 76-103. doi: 10.3390/ biom2010076. 
Orczewska-Dudek, S., Bederska-Łojewska, D., Pieszka, M., and Pietras, M. (2012). Cholesterol and lipid peroxides in animal products and health implications-a review. Annals of Animal Science, 12(1): 25-52. doi: 10.2478/v10220-012-0003-9

Osada, K., Sasaki, E., and Sugano, M. (1994). Lymphatic absorption of oxidized cholesterol in rats. Lipids, 29(8): 555-559. doi: 10.1007/BF02536627

Otaegui-Arrazola, A., Menendez-Carreño, M., Ansorena, D., and Astiasarán, I. (2010). Oxysterols: a world to explore. Food and Chemical Toxicology, 48(12): 3289-3303. doi: 10.1016/j. fct.2010.09.023.

Paniangvait, P., King, A. J., Jones, A. D., and German, B. G. (1995). Cholesterol oxides in foods of animal origin. Journal of Food Science, 60(6): 1159-1174. doi: 10.1111/j.1365-2621.1995. tb04548.x.

Papuc, C., Goran, G. V., Predescu, C. N., and Nicorescu, V. (2017). Mechanisms of oxidative processes in meat and toxicity induced by postprandial degradation products: a review. Comprehensive Reviews in Food Science and Food Safety, 16(1): 96-123. doi: 10.1111/1541-4337.12241

Phillips, J. E., Geng, Y. J., and Mason, R. P. (2001). 7-Ketocholesterol forms crystalline domains in model membranes and murine aortic smooth muscle cells. Atheroscleraosis, 159(1): 125-135. doi: 10.1016/S0021-9150(01)00504-4

Pie, J. E., Spahis, K., and Seillan, C. (1991). Cholesterol oxidation in meat products during cooking and frozen storage. Journal of Agricultural and Food Chemistry, 39(2): 250-254. doi: 10.1021/ jf00002a005

Pommier, A. (2010). Rôle du cholestérol et des récepteurs nucléaires LXRs dans le cancer de la prostate. Thèse Doctorat. Université Blaise Pascal, Clermont-Ferrand II, 401p.

Pordal, A. H., Hajmiresmail, S. J., Assadpoor-Piranfar, M., Hedayati, M., and Ajami, M. (2015). Plasma oxysterol level in patients with coronary artery stenosis and its changes in response to the treatment with atorvastatin. Medical journal of the Islamic Republic of Iran, 29: 192.

Raza, S., Meyer, M., Schommer, J., Hammer, K. D., Guo, B., and Ghribi, O. (2016). 27-Hydroxycholesterol stimulates cell proliferation and resistance to docetaxel-induced apoptosis in prostate epithelial cells. Medical Oncology, 33(2): 12. doi: 10.1007/ s12032-015-0725-5.

Rudzińska, M., Flaczyk, E., Amarowicz, R., Wąsowicz, E., and Korczak, J. (2007). Antioxidative effect of crackling hydrolysates during frozen storage of cooked pork meatballs. European Food Research and Technology, 224(3): 293. doi: 10.1007/s00217006-0443-5

Ryan, E., Chopra, J., McCarthy, F., Maguire, A. R., and O'brien, N. M. (2005). Qualitative and quantitative comparison of the cytotoxic and apoptotic potential of phytosterol oxidation products with their corresponding cholesterol oxidation products. British Journal of Nutrition, 94(3): 443-451. doi: 10.1079/BJN20051500

Samouris, G., Kasapidou, E., loannidou, M., and Eleftheriadou, A. (2011). Changes in lipid oxidation levels and fatty acid composition in the meat of milk-fed lambs during refrigerated and frozen storage-Nutritional indices. Archiv für Lebensmittelhygiene, 62(6): 217-222. doi: 10.2376/0003925X-62-217

Savage, G. P., Dutta, P. C., and Rodriguez-Estrada, M. T. (2002). Cholesterol oxides: their occurrence and methods to prevent their generation in foods. Asia Pacific Journal of Clinical Nutrition, 11(1): 72-78. doi: 10.1046/j.1440-6047.2002.00270.x

Schweizer, R. A., Zurcher, M., Balazs, Z., Dick, B., and Odermatt, A. (2004). Rapid hepatic metabolism of 7-ketocholesterol by $11 \beta$-hydroxysteroid dehydrogenase type 1: Speciesspecific differences between the rat, human and hamster enzyme. Journal of Biological Chemistry. 39p. doi: 10.1074/ jbc.M313615200

Serra, A., Conte, G., Cappucci, A., Casarosa, L., and Mele, M. (2014). Cholesterol and fatty acids oxidation in meat from three muscles of Massese suckling lambs slaughtered at different weights. Italian Journal of Animal Science, 13(3): 3275. doi:10.4081/ijas.2014. 3275

Serra, A., La Comba, F., Mele, M., and Secchiari, P. (2006). Influence of cooking on lipid oxidation of lamb meat. Progress In Nutrition, 8(1): 40-48.

Shao, W., and Espenshade, P. J. (2012). Expanding roles for SREBP in metabolism. Cell Metabolism, 16(4): 414-419. doi: 10.1016/j. cmet.2012.09.002

Shazamawati, Z. H., Alina, A. R., Mashitoh, A. S., and Juhana, M. T. (2013). Cholesterol oxidation products analysis in meat and poultry. Middle-East J. Sci. Res, 16: 67-78. doi: 10.5829/idosi. mejsr.2013.16.s.100212

Shibata, N., and Glass, C. K. (2010). Macrophages, oxysterols and atherosclerosis. Circulation Journal, 74(10): 2045-2051. doi: 10.1253/circj.CJ-10-0860

Silva, J., Dasgupta, S., Wang, G., Krishnamurthy, K., Ritter, E., and Bieberich, E. (2006). Lipids isolated from bone induce the migration of human breast cancer cells. Journal of Lipid Research, 47(4): 724-733. doi: 10.1194/jlr.M500473-JLR200

Smith, W. L., and Murphy, R. C. (2008). Oxidized lipids formed non-enzymatically by reactive oxygen species. Journal of Biological Chemistry, 283(23): 15513-15514. doi: 10.1074/jbc R800006200

Sottero, B., Gamba, P., Gargiulo, S., Leonarduzzi, G., and Poli, G. (2009). Cholesterol oxidation products and disease: an emerging topic of interest in medicinal chemistry. Current Medicinal Chemistry, 16(6): 685-705. doi: 10.2174/092986709787458353

Souidi, M., Dubrac, S., Parquet, M., Volle, D. H., Lobaccaro, J. M. A., Mathé, D., ... Aigueperse, J. (2004). Les oxystérols: métabolisme, rôles biologiques et pathologies associées. Gastroentérologie clinique et biologique, 28(3) : 279-293. doi: 10.1016/S03998320(04)94919-6

Sozen, E., Yazgan, B., Sahin, A., Ince, U., and Ozer, N. K. (2018). High cholesterol diet-induced changes in oxysterol and scavenger receptor levels in heart tissue. Oxidative Medicine and Cellular Longevity, 2018, 13. doi: 10.1155/2018/8520746

Spann, N. J., and Glass, C. K. (2013). Sterols and oxysterols in immune cell function. Nature Immunology, 14(9): 893. doi: 10.1038/ ni. 2681

Staprans, I., Pan, X. M., Rapp, J. H., and Feingold, K. R. (2003). Oxidized cholesterol in the diet is a source of oxidized lipoproteins in 
human serum. Journal of Lipid Research, 44(4): 705-715. doi: 10.1194/jlr.M200266-JLR200

Thurner, K., Razzazi-Fazeli, E., Wagner, K. H., Elmadfa, I., and Luf, W. (2007). Determination of cholesterol oxidation products in raw and processed beef and pork preparations. European Food Research and Technology, 224(6): 797-800. doi: 10.1007 /s00217-006-0372-3

Ubhayasekera, S.J.K.A. (2004). Cholesterol oxidation products: analytical methods and levels in sweets containing heated butter oil. Doctoral dissertation.

Verleyen, T., Dutta, P. C., Verhé, R., Dewettinck, K., Huyghebaert, A., and De Greyt, W. (2003). Cholesterol oxidation in tallow during processing. Food Chemistry, 83(2): 185-188. doi: 10.1016/ S0308-8146(03)00061-X

Vicente, S. J., Sampaio, G. R., Ferrari, C. K., and Torres, E. A. (2012). Oxidation of cholesterol in foods and its importance for human health. Food Reviews International, 28(1): 47-70. doi:1 $0.1080 / 87559129.2011 .594972$

Vine, D. F., Mamo, J. C. L., Beilin, L. J., Mori, T. A., and Croft, K. D. (1998). Dietary oxysterols are incorporated in plasma triglyceride rich lipoproteins, increase their susceptibility to oxidation and increase aortic cholesterol concentration of rabbits. Journal of Lipid Research, 39(10): 1995-2004.

Vladimiro, C., Casanova, O., Inchingolo, G., Banos Arias, S., and Estrada, R. (2016). Sex approach on lipid and cholesterol oxidation research in lamb meat. Doctoral dissertation. Bologna university.

Warns, J., Marwarha, G., Freking, N., and Ghribi, O. (2018). 27-hydroxycholesterol decreases cell proliferation in colon cancer cell lines. Biochimie, 153: 171-180. doi: 10.1016/j.biochi. 2018.07.006.

Wasowicz, E., Gramza, A., Hêœ, M., Jeleñ, H. H., Korczak, J., Maecka, M., ..., Zawirska-Wojtasiak, R. (2004). Oxidation of lipids in food. Pol J Food Nutr Sci, 13: 87-100.

Xu, G., Guan, L., Sun, J., and Chen, Z. Y. (2009). Oxidation of cholesterol and $\beta$-sitosterol and prevention by natural antioxidants. Journal of Agricultural and Food Chemistry, 57(19): 9284-9292. doi: 10.1021/jf902552s.

Xu, G., Sun, J., Liang, Y., Yang, C., and Chen, Z. Y. (2011). Interaction of fatty acids with oxidation of cholesterol and $\beta$-sitosterol. Food chemistry, 124(1): 162-170. doi:10.101 6/j.foodchem.2010.06.003

Yamanaka, K., Urano, Y., Takabe, W., Saito, Y., and Noguchi, N. (2015). Induction of apoptosis and necroptosis by 24 (S)-hydroxycholesterol is dependent on activity of acyl-CoA: cholesterol acyltransferase 1. Cell Death and Disease, 5(1): e990. doi: 10.1038/cd dis.2013.524.

Zhang, J., and Liu, Q. (2015). Cholesterol metabolism and homeostasis in the brain. Protein and Cell, 6(4): 254-264. doi: 10.1007/s13238-014-0131-3 